\title{
Erratum to: Human Vulnerability Mapping Facing Critical Service Disruptions for Crisis Managers
}

\author{
Amélie Grangeat ${ }^{1(\bowtie)}$, Julie Sina ${ }^{2}$, Vittorio Rosato ${ }^{3}$, Aurélia Bony ${ }^{2}$, \\ and Marianthi Theocharidou ${ }^{4}$ \\ ${ }^{1}$ CEA/GRAMAT, 46500 Gramat, France \\ amelie.grangeat@orange.fr \\ 2 Institut des Sciences des Risques - Centre LGEI, \\ Ecole des mines d'Alès, 30100 Alès, France \\ julie.sina@hotmail.fr, \\ aurelia.bony-dandrieux@mines-ales.fr \\ ${ }^{3}$ ENEA Casaccia Research Centre, Rome, Italy \\ vittorio.rosato@enea.it \\ ${ }^{4}$ European Commission, Joint Research Centre (JRC), \\ Via E. Fermi 2749, 21027 Ispra, VA, Italy \\ marianthi.theocharidou@ec.europa.eu
}

\section{Erratum to: \\ Chapter "Human Vulnerability Mapping Facing Critical Service Disruptions for Crisis Managers" in: \\ G. Havarneanu et al. (Eds.): Critical Information \\ Infrastructures Security, LNCS 10242, https://doi.org/10.1007/978-3-319-71368-7_9}

By mistake, the originally published version of the paper did not acknowledge that Marianthi Theocharidou is an employee of the European Union and that therefore the copyright on her part of the work belongs to the European Union. This has been corrected in the updated version.

The updated online version of this chapter can be found at https://doi.org/10.1007/978-3-319-71368-7_9 